\title{
Ideais de transcendência em poéticas de aniquilação: aspectos do sublime e da ironia em Camilo Pessanha e Pedro Kilkerry
}

\author{
Ideals of transcendence in poetics of annihilation: \\ aspects of the sublime and the irony in Camilo Pessanha and Pedro Kilkerry
}

\author{
FABIANO RODRIGO DA SILVA SANTOS \\ Universidade Estadual Paulista Júlio de Mesquita Filho - Assis - São Paulo - Brasil
}

27

\begin{abstract}
Resumo: As presentes considerações visam a investigar os pontos em comum entre a obras do poeta português Camilo Pessanha e do brasileiro Pedro Kilkerry, sob o prisma do sublime e da ironia, categorias ligadas ao idealismo romântico que, articuladas de maneira semelhante pelas poéticas de ambos, denotam a construção de projetos estéticos, por um lado, sintonizados com a modernidade e, por outro, sensíveis à tradição romântica. Sublime e ironia articulam-se em Camilo Pessanha e Pedro Kilkerry como recursos que visam superar as dificuldades de expressão do ideal e geram, em sua poesia, os motivos das ausências e da autoaniquilação. Tais motivos manifestam a consciência dos limites da expressão poética - fenômeno que corresponde a uma das características mais expressivas da poesia moderna. Assim, sua presença em Camilo Pessanha e Pedro Kilkerry demonstra que suas obras testemunham inquietações comuns à modernidade, superando muitas das convenções da poesia de seu tempo.
\end{abstract}

Palavras-chave: Simbolismo português; Simbolismo brasileiro; Sublime; Ironia; Modernidade

\begin{abstract}
These considerations aim to investigate the commonalities between the oeuvres of the portuguese poet Camilo Pessanha and the brazilian Pedro Kilkerry from the perspective of the sublime and irony, related categories to the romantic idealism that are manifested similarly in both poetries, denoting the construction of aesthetic projects, first, in line to modernity, second, sensitive to romantic tradition. Sublime and irony are aligned in Camilo Pessanha and Pedro Kilkerry as resources that aimed at overcoming the difficulties of expression of the ideal and build, in their poetry, the motives of the absences and self-annihilation. These motives manifest the consciousness of the limits of the poetic expression - a phenomenon which corresponds to one of most expressive characteristics of the modern poetry. Thus, its presence in Camilo Pessanha and Pedro Kilkerry demonstrate that their oeuvres testify to common concerns of modernity, overcoming many of the conventions of the poetry of their time.
\end{abstract}

Keywords: Portuguese symbolism; Brazilian symbolism; Sublime, Irony; Modernity

Camilo Pessanha (1867-1926) e Pedro Kilkerry (1885-1917), embora separados pelos contextos oferecidos por suas respectivas literaturas nacionais, são poetas que compartilham muitas semelhanças; contemporâneos, ambos se inscrevem como expressões singulares da poesia simbolista em seus meios, sendo tratados pela crítica como poetas em que se insinuam aspectos maduros da poesia da modernidade ${ }^{1}$. Além

\footnotetext{
1 O juízo sobre a modernidade de Camilo Pessanha e Kilkerry foi referenda por poetas vinculados diretamente a renovação da poesia em língua portuguesa. Camilo Pessanha conta, inclusive, com a apreciação dos inauguradores do modernismo português; Fernando Pessoa, por exemplo, o vê, ao lado de Antero de Quental e Cesário Verde, como um dos responsáveis por abrir novos rumos na poesia portuguesa, sendo
}

disso, ambos se relacionaram de modo semelhante com as agremiações literárias de seu tempo; Camilo Pessanha, residindo em sua maturidade no exílio em Macau, era figura fragilmente integrada aos meios intelectuais portugueses (GUIMARÃES, 1992, p. 31), ao passo que Kilkerry, poeta de província, contou com uma circulação muito restrita de sua obra, sendo divulgado apenas ao grande público tardiamente (CAMPOS, 1985). As

responsável pelo desenvolvimento de uma linguagem de sugestão, que torna possível intelectualizar sentimentos (PESSOA apud FRANCHETTI, 2009 , p. 25), processo que denota uma consciência critica do fazer poético. Já Pedro Kilkerry é tratado por Augusto de Campos como um poeta que acessou de modo autêntico os dispositivos mais sofisticados do simbolismo, como a sondagem do inconsciente (CAMPOS, 1985, p. 41). 
relações tangenciais que estabeleceram com os meios literários dominantes de suas épocas, por um lado, tem reflexo no percurso igualmente acidentado da recepção de suas obras; Camilo Pessanha publicou seus poemas em periódicos portugueses desde fins do século XIX, contudo, o conjunto de sua produção apenas chegaria a livro em 1920, sob os auspícios de Ana de Castro Osório, em uma edição intitulada Clepsidra, cuja organização deu-se de modo arbitrário, a partir de poemas esparsos e autógrafos originais (FRANCHETTI, 2009). Já Kilkerry nunca contou com a publicação de seus poemas em livro, devendo-se a integração de sua obra conhecida em um único volume a Augusto de Campos, que publica a "revisão" de seu trabalho, sob o título de Re-visão de Kilkerry, em 1970 (CAMPOS, 1985).

Por outro lado, o relativo isolamento de Pessanha e Kilkerry pode ter assegurado a autonomia necessária para que sua poesia não aderisse plenamente às convenções que o simbolismo assumiu em seus meios, sendo essa uma das prováveis razões de sua reconhecida originalidade. Com efeito, tratam-se de autores muito singulares em seu tempo e que adentraram a sensibilidade de leitores pósteros. Embora Camilo Pessanha tenha desfrutado de reconhecimento ainda em vida, os principais apreciadores de sua lírica estão entre aqueles que ditariam os rumos da nova poesia portuguesa, a saber, os grupos modernistas que orbitaram em torno das revistas Centauro e, sobretudo, Orpheu (GUIMARÃES, 1992, p. 28-35); já Kilkerry, a despeito de figurar como estranho poeta simbolista em antologias e estudos panorâmicos consagrados ao movimento no Brasil, encontraria maior acolhida no contexto da poesia de vanguarda do país, como demonstra a admiração dos concretistas brasileiros por sua obra, com especial destaque a seu maior estudioso, Augusto de Campos².

Em um primeiro momento, a aproximação entre poetas pertencentes a contextos tão distintos, como são Camilo Pessanha e Pedro Kilkerry, pode parecer destinada ao fracasso ou a soçobrar em gratuitismo. Afinal, embora compartilhem a mesma língua, sejam contemporâneos e tenham adotado um referencial estético comum - o simbolismo - cada qual deles formou-se em ambientes culturais que, entre fins do século XIX e início do século $\mathrm{XX}$, trilhavam caminhos autônomos. A literatura brasileira já dera largos passos em busca de sua emancipação

\footnotetext{
Seus primeiros divulgadores, Jackson de Figueiredo e Carlos Chiacchio, emitiram juízos acerca de sua singularidade, considerando-a como notas de uma madura compreensão da estética simbolista. Opinião compartilhada por Andrade Muricy (1987) quando o incorpora a seu Panorama do movimento simbolista, de 1957. No entanto, a maneira como Pedro Kilkerry passou a ser visto pela crítica deve-se muito aos esforços de Augusto de Campos, que coligiu e recuperou tudo o que foi possível da esparsa e fragmentária obra do poeta, realizando a análise de suas produções sob perspectiva sensível aos dispositivos nela presentes que desembocariam na diç̧ão poética da vanguarda.
}

frente à literatura da antiga metrópole, enquanto que a literatura portuguesa, em épocas de hierarquização cultural, dificilmente beberia do manancial oferecido pela produção de uma ex-colônia.

Não se pode afirmar que não haja relações cambiantes entre as duas literaturas nesse período; de fato, existiam, mas se limitavam, como é de se presumir, a autores de grande renome, e principalmente envolviam a ressonância dos autores portugueses nos meios letrados brasileiros. Dificilmente, contudo, autores de circulação restrita como Camilo Pessanha e, sobretudo, Pedro Kilkerry, transporiam as barreiras entre os dois contextos. Aliás, o intercâmbio entre os dois poetas seria praticamente impossível, já que Camilo Pessanha, mesmo tendo publicado seus poemas em jornais portugueses desde a década de 1890, só tem sua obra compilada em volume em 1920, quatro anos após a morte de Kilkerry. Esse, por seu turno, não logrou reconhecimento para além de um restritíssimo grupo de escritores baianos, já que sua obra, publicada esparsamente em periódicos da Bahia, entre os anos de 1905 e 1917, manteve-se praticamente desconhecido do grande público até os anos de 1970.

No entanto, ambos compartilham semelhanças em relação ao que sua poesia representa a suas literaturas nacionais - tanto Camilo Pessanha como Pedro Kilkerry são reconhecidos pela crítica como renovadores da dicção poética em língua portuguesa, assinalando a eclosão de uma poesia moderna que, aliás, no caso de Pessanha em relação à moderna poesia portuguesa, conta com reconhecimento (como dito, as revistas de vanguarda Centauro e Orpheu, estamparam poemas de sua autoria e há francas manifestações de admiração de sua obra por parte de Fernando Pessoa e Mário de Sá-Carneiro). Diferentemente do que se deu a Pedro Kilkerry, que contou com reconhecimento tardio.

As semelhanças entre Camilo Pessanha e Pedro Kilkerry, pois, não parecem ser fortuitas; ambos formaram sua sensibilidade estética sob os influxos do simbolismo francês e em ambientes em que essas influências saturaram-se em convenções e modismos, tornando-se, por vezes, pendor um tanto postiço de certos grupos literários que, ao invés de explorarem as possibilidades experimentais da estética, engessaram sua forma e adequaram-na à conveniência sensível ao gosto instituído. Em Portugal, os carros-chefe do movimento, representados pelos poetas que orbitaram, por exemplo, em torno dos periódicos Boêmia nova e Os insubmissos, ou mantiveram-se muito fieis ao simbolismo francês, em especial às formulações de Jean Moréas (como é o caso de Eugênio de Castro), ou buscaram a autonomia poética em um retorno às tradições locais, ao saudosismo e ao provincianismo, como é caso de António Nobre e António Patrício, atitude que, embora assegure uma dicção própria 
ao simbolismo português, não assinala grandes novidades frente ao quadro da poesia nacional, visto ligar-se muito de perto à herança do romantismo. Já no contexto brasileiro, o simbolismo manteve-se como manifestação poética menor, crescendo à sombra do parnasianismo e nutrindo-se de muitas de suas práticas.

É precisamente contra o pano de fundo oferecido pelo contexto de suas literaturas nacionais que a singularidade das obras de Camilo Pessanha e de Pedro Kilkerry se destaca, podendo ser vistas como manifestações de uma poesia simbolista consciente, produto de um projeto autônomo e, mau grado sua difusão fragmentária, autointegrado. Em ambos, por exemplo, ritmos muito pessoais chocam-se contra os limites da metrificação, moldando-a de acordo com os propósitos dos poemas; suas experiências vão muito além de deslocamentos de cesuras em metros alexandrinos (praticados como novidade pelos simbolistas franceses e também por portugueses e brasileiros, embora implique mudança artificial no plano da língua portuguesa), da exploração das possibilidades do decassílabo ou do recurso das aliterações; em seus poemas encontra-se a subordinadação da sintaxe à musicalidade evocada pelas próprias imagens do poema, manifestadas em reiterações de termos e paralelismos que dão vozes a ecos e silêncios.

Além disso, o lirismo de Pessanha e Kilkerry furta-se ao confessionalismo de fundo romântico, preservado no âmbito da subjetividade simbolista, e ao descritivismo ornamental parnasiano; em seu lugar, a matéria íntima é sintonizada com impressões exteriores por nexos oblíquos e imprecisos. Desse modo, a poesia tanto de um como de outro consegue explorar com originalidade o caráter sugestivo da linguagem simbolista.

O ritmo das correspondências herméticas dita a imagética de seus poemas, dando corpo a motivos (comuns a Pessanha e Kilkerry) relacionados ao esforço de plasmação do ideal (que resvala no silêncio) e à busca por transcendência no aniquilamento e diluição do eu em impressões alucinatórias. Por essas razões, Camilo Pessanha, em Portugal, e Pedro Kilkerry, no Brasil, estão entre aqueles poetas que oferecem desafio à chave de leitura oferecida pela escola simbolista regular (e no caso do Brasil, pelo parnasianismo), visto ampliarem os horizontes das orientações estéticas dessa corrente, superando as convenções instituídas em seus respectivos países. Com efeito, no que tange a Kilkerry, essa característica foi reconhecida por Augusto de Campos:

Se bem que as obras de poetas parnasianos figurassem entre as suas leituras, e chegasse a traduzir um poema de Heredia (...), o fato é que as suas realizações e experiências refogem por completo à estética parnasiana, para se situarem entre aquelas que caracterizam uma poesia integralmente simbolista; ao mesmo tempo já prefiguram a superação do próprio Simbolismo, transpondo aqui e ali os limites que o separam dos movimentos modernos (...) (CAMPOS, 1985, p. 30)

Embora não haja relações de confluência entre Pessanha e Kilkerry, há muitos procedimentos estéticos, motivos e características comuns a suas obras que demonstram terem compartilhado de um mesmo referencial estético que não se limita às influências simbolistas francesas, mas remontam aos arrimos estético-filosóficos do idealismo romântico. Camilo Pessanha e Pedro Kilkerry são poetas idealistas às voltas com a saturação das convenções romântico-simbolistas em seus meios literários (e, consequentemente, com a crise do idealismo), que buscaram a autonomia de sua obra justamente na exploração profunda do repertório idealista, encontrando nele vias de acesso a uma nova dicção poética. Duas categorias estéticas, exploradas com consciência e desenvoltura pelos dois poetas, atestam os vínculos de seu projeto estético com o idealismo o sublime e a ironia, que tanto em Camilo Pessanha, como em Kilkerry, unem-se para dar corpo a sugestões e imagens alucinatórias em que a imprecisão denota a tentativa de plasmar o ideal e o inexprimível.

Camilo Pessanha, sob o signo da melancolia, dos conflitos que tem por arena a vontade e das notas do exílio e da saudade, busca a transcendência mediante a exploração das livres associações de imagens (RUBIM, 1993), movimento semelhante ao operado por Kilkerry, que encontra na exploração vertiginosa da imagem, ora com acentos melancólicos, ora de modo eufórico, as vias para a aniquilação e diluição do eu na vertigem das impressões. Em comum entre os dois poetas é a sutileza com que sua poesia busca, ao explorar nas imagens do cotidiano, na contemplação metonímica da natureza (por exemplo, nas impressões fornecidas pela força aniquliadora do mar, pelo ritmo das estações, pelas horas do dia, pelo fluxo das águas) ou na matéria íntima (que sugerem mesmo nexos bibliográficos), vias alternativas para transcender os limites do verbo e alcançar o ideal, mesmo que reconhecendo a dificuldade (ou impossibilidade) de tal tarefa.

Com efeito, a sensação de frustração emerge em quase toda a Clepsidra e em muitos dos poemas de Pedro Kilkerry. Em Kilkerry assume, por vezes, as formas explícitas do silêncio e do nada, contra os quais se insurge, em alguns momentos, a metalinguagem. Já em Pessanha, a falência do ideal parece possuir os contornos do trânsito de impressões que não se fixam, na constatação da virtualidade da existência que encaminha seu ideal poético à aniquilação fatalista, superficialmente representada pela morte. 
Acima do conflito entre os limites das impressões e a vastidão do ideal, paira o sublime, o qual apenas pode ser materializado indiretamente, pelo anseio por autoaniquilação, esforço esse que parece encaminhar a poesia de Pessanha e de Kilkerry às abstrações.

O sublime assume em Camilo Pessanha e Kilkerry contornos muito distintos do que comumente se observa na poesia romântica que também o cultivou. Não se trata mais de um mecanismo de arrebatamento pela exaltação ou retrato das altas imagens e sentimentos, mas sim de um esforço em registrar o além, o ideal, perante o qual todas as formas de expressão diretas falham; por isso a escolha da sugestão, o pendor pelo vago, pelas formas imprecisas e por um retrato impressionista da realidade. Pessanha e Kilkerry demonstram ser idealistas conscientes dos obstáculos que existem entre o verbo poético e a idealidade; nesse ponto, atestam sua modernidade e autores de uma poesia cuja compreensão demanda a investigação das bases idealistas da poesia moderna.

Como categorias de ressonância tanto na sensibilidade romântica como moderna, é natural que o sublime e a ironia permeiem toda a poesia ocidental, desde pelo menos meados do século XIX. De modo que os pares de Camilo Pessanha e Kilkerry também apresentam notas de ambas. No entanto, Pessanha e Kilkerry, diferentemente da média dos poetas simbolistas e parnasianos portugueses e brasileiros, utilizam-nas como categorias interdependentes, valendo-se dos recursos expressionais da ironia para acentuar as possibilidades do sublime, constituindo, assim, uma dicção nova. Não se trata mais de emular os efeitos impactantes da poesia romântica ou buscar atingir as altas esferas na eleição de grandes temas e na exploração de imagens grandiosas e raras; mas, sim, encontrar nas imagens mais simples, colhidas das experiências acessíveis, os meios para se eclodir o momento de arrebatamento sublime e tematizar a transcendência. Além disso, o sublime permeado pela ironia confere aos dois poetas a consciência dos limites da expressão poética, criando pontos de contato entre o absoluto e o nada.

Em Pedro Kilkerry tal consciência se revela em alguns momentos de maneira muito sintonizada com a sensibilidade moderna, ao valer-se do discurso autorreferente; já em Camilo Pessanha ela manifesta-se em consonância com uma forma de angústia metafísica que, em seus poemas, envolve as tentativas vãs de se domar a vontade e diluir-se no absoluto. Curiosamente, quando se consideram as heranças do romantismo à poética da modernidade, a ironia se sobressai como tônica, enquanto o sublime soa como ultrapassado (WEISKEL, 1994, p. 21). Desse modo, em Camilo Pessanha e Pedro Kilkerry, igualmente, a convivência íntima entre sublime e ironia pode ser tratada como via de interpretação de sua modernidade, visto trazer à baila contradições e paradoxos, próprios da modernidade, principalmente aquele reconhecido como central - o conflito entre permanência e renovação.

Em outras palavras, a questão da modernidade em Camilo Pessanha e Pedro Kilkerry é campo aberto para discussões que perpassam os alicerces românticos de sua poesia, por ela revisitados mediante a complexa e dialética dinâmica que, conforme estudiosos como Antoine Compagnon (1995), Matei Calinescu (1991) e Octávio Paz (1994), movimenta a modernidade: a saber, a tensão entre a tradição e o novo.

A modernidade em Camilo Pessanha e Pedro Kilkerry apresenta-se como uma não radical negação das convenções estéticas do meio, contudo, em relação ao repertório filosófico e estético de base romântica (depurado pelo simbolismo) coloca-se como parte de um processo paulatino de ampliação e transformação que contribui aos mecanismos expressionais da poesia que se tornará praxe no século XX. Como tal, a avaliação da modernidade de Camilo Pessanha e Kilkerry perpassaria, inevitavelmente, a consideração de categorias estéticas, e suas materializações em sua obra, que denotassem o processo de constituição de uma lírica moderna; no caso preciso, o sublime e a ironia. A permanência dessas categorias na poesia dos dois autores seria suficiente para demonstrar a originalidade deles face seu meio, um dos pendores de sua alegada modernidade. Além disso, sublime e ironia estão na base do pensamento estético moderno, ocupando as discussões do idealismo romântico que indiretamente influi sobre os dois poetas, via simbolismo francês, e mesmo mais de perto, graças à ressonância do pensamento de Schopenhauer. Ora, é reconhecida a influência de Schopenhauer sobre Camilo Pessanha (FRANCHETTI, 2009, p. 13) e os biógrafos de Kilkerry reconhecem entre suas leituras não exatamente Schopenhauer, mas de Friedrich Nietzsche (FIGUEIREDO apud CAMPOS, 1985, p. 23), esse tributário àquele.

Os influxos do repertório filosófico do idealismo romântico sobre Camilo Pessanha e Pedro Kilkerry se manifestam, como dito, precisamente na plasmação de motivos estéticos ligados às categorias do sublime e da ironia. Como se tratam de categorias divergentes, conflitantes entre si e passíveis de inúmeras definições, faz-se necessário delinear as acepções de sublime e ironia que orientam nossas considerações.

A primeira, e talvez mais problemática (dentro do contexto de leitura aqui proposto), dessas categorias é o sublime. Herança das poéticas da antiguidade, o sublime adentra o pensamento estético moderno, enfeixando as reflexões sobre o caráter transcendente da beleza. Os pensadores da ilustração estiveram às voltas com sua inves- 
tigação, tomando como base um texto da antiguidade, então redescoberto: $O$ tratado do sublime (Peri Hypsous), cuja autoria é atribuída a Longino. Em Longino, o sublime é considerado recurso poético a serviço de uma retórica de arrebatamento da sensibilidade do leitor, manifestada na ênfase da matéria mais elevada, com a finalidade não de convencer o espectador, mas de exaltá-lo, compartilhando com ele a sensação de grandeza que envolve o objeto tratado pela obra (LONGINO, 1996, p. 54).

A partir da leitura de Longino, o sublime adentra o ambiente da ilustração, entre fins do século XVII e o século XVIII, como a manifestação poética do elevado; assim ocorre, por exemplo, com a maneira como o conceito é visto por Boileau, responsável pela introdução do termo "sublime" (tradução de Hypsous - "grandeza", "enlevo", termo utilizado por Longino).

A novidade em relação ao sublime e a reincidência de seu tema no pensamento estético do século XVIII provavelmente se deve ao fato de se tratar de um conceito oriundo da antiguidade, que, ao contrário dos postulados (para usar uma palavra talvez anacrônica) normativos interpretados a partir da poética de Aristóteles e da Carta aos Pisões, de Horácio, deixava entrever questões relativas à recepção e ao efeito estético.

Quando os estetas ingleses se dedicam à investigação do termo, o sublime assume precisamente as conotações de uma beleza alcançada nos extremos, que coloca em evidência as relações entre a sensibilidade humana e a beleza subjacentes ao entendimento, que, no sublime, transpõem os limites do simples prazer, encontrando correspondência em uma convivência ambígua do aprazível com o ameaçador. Assim é com a leitura do sublime feita por Edmund Burke (1993), cujas considerações presentes em Uma investigação filosófica sobre a origem de nossas ideias do sublime e do belo (1757), ao inspirar (no que se refere ao sublime) a Crítica do Juízo (1790), de Kant, legará aos filósofos alemães um conceito profícuo para a compreensão não apenas do belo, mas das próprias categorias associadas ao entendimento humano e sua relação com a realidade.

O sublime adentra o contexto do pensamento alemão moderno (culminando em reflexões importantes para a constituição do romantismo) como uma via tortuosa pela qual se poderia chegar às ideias, distanciando-se dos corrimãos oferecidos pela lógica racional.

Para Kant o sublime nasceria da constatação de que a compreensão humana, frente a fenômenos sensoriais de grandiosidade imensurável, possui limites, não podendo abarcar todos os aspectos da realidade. O sublime constituiria um desafio também à imaginação, a qual, ante a perspectiva do infinito, própria do sublime, falharia em representá-lo concretamente; tal impossibilidade transportaria o homem diretamente à instância das ideias, na qual o sublime então poderia ser entrevisto (KANT, 1961, p. 87). Grosso modo, poder-se-ia colocar sob a égide do sublime todos os fenômenos nos quais se vislumbre a infinitude. $\mathrm{O}$ sublime seria, portanto, manifestação e o efeito da grandeza (KANT, 1961, p. 89-91). Assim, o sublime distinguir-se-ia do belo justamente pela maneira com que ambos se apresentam ao entendimento. O belo seria apreensível em sua totalidade, como objeto harmonioso e circunscrito ao entendimento da imaginação e, como tal, aprazível; já o sublime, ao revelar o infinito, em contraponto, evidenciaria os limites da imaginação e do entendimento, gerando uma experiência, por vezes, opressiva e terrificante, porém, solene, que desperta a comoção e o respeito (KANT, 1961, p. 80-85). A partir desse ponto, Kant observa a existência de duas formas de sublime: o matemático, experiência que se tem quando a imaginação se confronta com algo de dimensões incomensuráveis e o dinâmico, suscitado pelos espetáculos naturais que revelam os poderes absolutos da natureza. O sublime kantiano, desse modo, manifesta-se em tudo aquilo que oprime a imaginação seja por seu tamanho, seja por sua potência.

Dominante em todo o romantismo, a busca pelo sublime, ou a crença em suas potencialidades, sofreu gradativa atenuação ao longo da modernidade. Isso, pois, a premissa do sublime depende de uma crença nas faculdades transcendentes da arte (WEISKE, 1994, p. 17), que se torna exígua conforme se delineia o ideário moderno. Ora, desviado de seus rumos idealistas pelo utilitarismo do discurso político, patriótico ou religioso, o sublime, moderna e contemporaneamente, corre sérios riscos de resvalar no Kitsch, sendo aparentemente pequena a adesão ao seu apelo por poetas de gerações posteriores ao romantismo. Além disso, as condições próprias da produção artística da modernidade, que atestam o esvaziamento dos contornos de especialidade conferidos à obra de arte - fenômeno teorizado por Walter Benjamin (1994) sob o conceito de aura -, parecem desferir o golpe capital sobre o sublime. Talvez por isso as considerações sobre essa categoria figurem muito pouco na análise da arte e nos programas estéticos a partir da segunda metade do século XIX. Assim, paira a impressão de que o sublime seria uma categoria morta, chegando-se mesmo a questionar sua validade conceitual e existência. Tal constatação tornaria a categoria inadequada para a consideração de autores tratados sob perspectiva moderna, como é caso da leitura que aqui se propõe da obra de Camilo Pessanha e Pedro Kilkerry. No entanto, a herança romântica subjaz no projeto estético dos dois poetas, bem como em muitos dos artistas modernos, sendo possível observar neles, por isso, ecos do sublime; uma forma de sublime, contudo, revista sob a égide da criticidade característica da poesia moderna. 
Com efeito, Thomas Weiskel reconhece que a sensibilidade pós-romântica é pouco afeita ao sublime, sendo ainda, todavia, passível de apreendê-lo, mesmo que, em suas palavras, de modo "abreviado", "reduzido" e "parodiado" como grotesco e "contido" pela ironia (WEISKEL, 1994, p. 21). Sob esse ponto de vista, grotesco e ironia, outras duas categorias importantes para a constituição do romantismo, embora opostas ao sublime, dada a sua grande força no contexto da modernidade, paradoxalmente, oferecem sombra para que o sublime viceje em solo moderno. Charles Baudelaire, quando canta seu "Idéal" (BAUDELAIRE, 1942, p. 98), por exemplo, ao reivindicar à sua poesia o vigor do Prometeu de Ésquilo ou do estatuário renascentista, materializado na referência à Noite de Michelangelo, reivindica o sublime junto a sua poesia francamente irônica. Aliás, o poeta dá nota da convivência tensa entre ironia e sublime na figura de seu frágil albatroz (BAUDELAIRE, 1942, p. 85) que exilado na terra, grotesco e ridículo, ressente-se da impossibilidade de andar, justamente por ser constrangido por suas asas imensas, pertencentes à esfera do sublime.

É, pois, sob o signo dessa tensão e ambivalência que a aspiração ao ideal irá conviver, na modernidade, com a ironia. A poesia moderna parece visar a beleza que reside além das fronteiras da convenção, buscando-a, seja nas elevações do sublime ou nas tramas contraditórias da ironia.

O conceito de sublime adotado em nosso trabalho refere-se, pois, aos recursos de expressão que, apropriando-se de uma imagética tradicionalmente instituída no romantismo, buscam criar efeitos de grandiosidade, elevação e, sobretudo, transcendência, com a finalidade de dar corpo ao substrato metafísico e idealista da poesia. Tratamos o sublime não como uma realização poética, mas uma espécie de possibilidade estética, entrevista no uso de certos motivos que evocam a beleza que reside no inquietantemente grandioso e no transcendente.

Em Camilo Pessanha, o sublime surge, frequentemente, nos poemas que tematizam o aniquilamento da subjetividade, desenvolvido em consonância com as buscas por supressão do conceito de vontade, postulado por Schopenhauer $(2003$, p. 106). Pode-se tomar como exemplo, os poemas "Vênus" e "Singra o navio sob a água clara", em que se observa a atribuição de força aniquiladora ao mar, retratado em uma imagética própria aos conceitos de sublime dinâmico e matemático. Os dois poemas, como constatou Paulo Franchetti (2009, p. 46-60), compõem um dístico e, com efeito, as mesmas imagens marinhas ecoam de um para outro. No primeiro soneto, "Vênus", desde o título, evoca-se a imagem feminina da deusa do amor que emerge das águas; contudo, tal imagem perde-se no turbilhão confuso do mar, materializado por seus movimentos febris, em consonância com imagens grotescas e agressivas, como "Pútrido ventre, azul e aglutinoso" (PESSANHA, 2009, p. 32), que dá corpo ao mar, ou "as feras que mugem" (PESSANHA, 2009, p. 32), que evocam a violência das vagas. A violência desse soneto ecoa na placidez inquietante do segundo, reproduzido abaixo:

Singra o navio. Sob a água clara Vê-se o fundo do mar, de areia fina... - Impecável figura peregrina,

A distância sem fim que nos separa! Seixinhos da mais alva porcelana, Conchinhas tenuemente cor de rosa, $\mathrm{Na}$ fria transparência luminosa

Repousam, fundos, sob a água plana. E a vista sonda, reconstrui, compara, Tantos naufrágios, perdições, destroços!

- Ó fúlgida visão, linda mentira!

Róseas unhinhas que a maré partira...

Dentinhos que o vaivém desengastara...

Conchas, pedrinhas, pedacinhos de ossos...

(PESSANHA, 2009, p. 32-33)

Nesse soneto delineiam-se as impressões de um mar plácido e infinito que, por contraste, evoca todos os desastres: "e a vista sonda, reconstrui compara/ tantos naufrágios/perdições, destroços!", culminando em uma irônica associação entre as conchas e minerais marinhos - retratados por ternos diminutivos -, com fragmentos da morte: "pedacinhos de ossos"; em movimento de gradação que encaminha as imagens do poema da placidez ao pathos, turbando a calmaria do mar, com a visão metonímica da morte que abre o poema a uma sutil forma de sublime: "Róseas unhinhas que a maré partira.../dentinhos que o vai e vem desgastara.../ conchas, pedrinhas, pedacinhos de ossos....". Como se pode notar, nesse poema, o mar promove a morte, mas assimilando a vida diluída à sua matéria, sorvendo-a como componente de sua infinitude - infinito e potência, eis a imagem do mar que articula, respectivamente os conceitos kantianos de sublime matemático e dinâmico, que aqui se manifestam indiretamente no ritmo das ondas indiferentes à aniquilação do elemento humano.

Pedro Kilkerry também cantou a autoaniquilação em termos semelhantes; por exemplo, em seu poema "Harpa esquisita", em que o eu lírico, em solilóquio, constrói seu processo de diluição e sublimação no ritmo das notas tangidas em uma harpa. Em associações vertiginosas, o céu noturno e o mar fundem-se como instâncias diluidoras da angústia e da dor que move o canto do poeta: 
(...)

Um lírio de ouro se alça?...Os passos voam-te, pelas Ribas...Oh! que ilusões da flor, que tantaliza!

Sobe a flor? Sobes tu e a alma nas pedras pisa?.... Pairas... Em frente, o mar, polvos de luz - estrelas...

Pairas... e o busto a arfar - longe, vela sem norte. Negro o céu desestrela, o seio arqueado: escuta. No amoroso oboé solveja um vento forte E, alta, em surdo ressôo, a onda betúmea e bruta.

A ânsia do mar, lá vem, esfrola-se na areia... Seu líquido cachimbo é mágoa acesa, e fuma! E chamas a onda: "irmã!". E em fósforo incendeia Na praia a onda do mar, ri com dentes de espuma

(...)

Gemes... Dedando o Azul as magras mãos dos astros Somem, luzindo... Ao longe, esqueleta uma ruína Em teu sonho a anervar argentina, argentina...

De ilusões, no horizonte, ossos brancos... são mastros! (...)

(KILKERRY, 1985, p. 106)

Por meio da evocação de imagens ascendentes em um paradoxal naufrágio nas alturas, o poeta celebra a morte e a diluição, do que chamara no primeiro verso de dor "da festa da verdade da vida", ao dizer: "quente estiras a alma, à frialgem, nas cousas.../que bom morrer!manhã, luz remada sonora.../Pousas um dedo níveo às níveas cordas, pousas E és naufrago de ti, a harpa caída, agora" (KYLKERRY, 1985, p. 106). Tal processo culmina em uma espécie de nirvana, em que a consciência se perde, ofuscada pelo brilho incandescente do ouro: "mais que um devirxe, és um deus, que morre, a irradiosa/glorificação de ouro e o sol de ouro.... à paz do ouro."(KILKERRY, 1985, p. 107). O percurso sublime do poema não utiliza apenas imagens convencionais de elevação, mas precipita-se na imagética do insólito, fundindo mar e estrelas na imagem dos "polvos de luz", e divisando ao longe ruínas e mastros de navios como ossadas: "Ao longe, esqueleta uma ruína/ em teu sonho a anarvar, argentina, argentina.../de ilusões, no horizonte, ossos brancos...são mastros!" em uma estranha Fata Morgana (KILKERRY, 1985, p. 105).

O sublime em Kilkerry, como se observa, nutrese das alucinações e de imagens dúbias e estranhas, materializadas por uma profusão de neologismos igualmente estranhos. Há nele, pois, uma experimentação e exploração de contrastes que se vale com frequência dos recursos da ironia. Com efeito, a categoria da ironia apresenta-se tanto a Camilo Pessanha como a Kilkerry como combustível para o sublime.

A importância da ironia para a estética moderna figura em estudos consagrados sobre o fenômeno, tais como Estrutura da lírica moderna, de Hugo Friedrich (1978) e Filhos do Barro, de Octávio Paz (1994), trabalhos em que a categoria surge como uma das linhas de força da modernidade. A ironia moderna vai além do discurso velado e oblíquo que a caracteriza como figura de retórica. Trata-se antes de uma autoconsciência crítica que se manifesta nas obras mediante o reconhecimento do caráter lúdico e artificioso da arte, problematizando os limites das convenções estéticas e da relação da obra com a vida e explorando contradições e pontos de dissonância no discurso (MUECKE, 1995, p. 38-39).

Essa leitura da ironia é amparada por um conceito cunhado em ambiente romântico, incorporando o adjetivo a sua alcunha. A chamada ironia romântica foi mais precisamente conceituada por Friedrich Schlegel e em seu pensamento é definida como uma espécie de consciência do caráter lúdico da obra de arte. A ironia no pensamento de Schlegel surge mesmo como uma palavra de ordem, uma categoria necessária à renovação da estética, tanto que em sua obra Conversa sobre a poesia (1800) é exposto o programa romântico de recobrir toda a produção estética, das mais sérias e pretensiosas às mais populares, pelo ludismo labiríntico da ironia (SCHLEGEL, 1994, p. 58).

Contrapondo realidades distintas por meio da união de gêneros (como por exemplo, no tragicômico) ou evidenciando o artificialismo dos produtos estéticos por meio de intervenções metatextuais e nesse processo, algumas vezes, ficcionalizando o próprio real, os artistas românticos valem-se dos expedientes da ironia para submeter a arte à ótica do jogo. Segundo o filósofo italiano Gianni Vattimo, a ironia é de grande importância para o romantismo por expressar a autorreferência na arte, discurso esse apropriado aos ideais de autonomia artística e à concepção de arte como mecanismo de reflexão filosófica (VATTIMO, 1985, p. 36).

A ironia parece necessária à arte idealista, pois essa concebe a vida como um jogo de simulacros e ilusões, demandando, por isso, uma linguagem lúdica que poderia ser capaz de captar-lhe o essencial. Ora, sob perspectiva idealista, a ironia seria um meio de se alcançar às instâncias inteligíveis através do jogo com as representações do real - por meio do distanciamento dos objetos de observação, sejam eles exteriores ou internos ao indivíduo, o ironista poderia avaliar criticamente o real, exercendo inclusive a autocrítica. Concebida por Schlegel como uma forma de "bufonaria transcendental", a ironia seria um modo de se evidenciar a verdade.

Os elementos que sobrevivem aos jogos irônicos depurariam a percepção da verdade. Em uma instância mais individual, a ironia seria um recurso ainda mais preciso, visto que, ao empreender o distanciamento de si próprio, através da autoparódia, o ironista vê-se mais apto ao autoconhecimento - nesse caso a distância é um ângulo privilegiado para a consciência. É precisamente como instrumento a serviço de um olhar crítico e relativo 
que busca o desvelamento do real que a ironia é vista em contexto romântico, tal desvelamento nutre-se da evidência de contradições, sendo esse aspecto interessante às investigações aqui propostas.

A despeito de predominar na dicção de Camilo Pessanha a nota melancólica, em alguns momentos de sua poesia a perspectiva irônica encontra relevo. É precisamente via ironia que se constroem os contrastes da obra de Pessanha que permitem a evocação do sublime junto às impressões cotidianas e também e o tema do consolo na morte e no olvido; desse modo, a ironia surge, algumas vezes, como tônica de seus poemas que tematizam a autoaniquilação. Nesses poemas, o eu lírico de Pessanha, passivo e resignado, é esmagado pelo tropel da morte e da diluição, apresentando, nos mesmos quadros, em contraponto, o turbilhão frenético da vontade. Como exemplo, pode-se tomar o poema cujo primeiro verso é: "porque o melhor enfim, é não ouvir nem ver...."
Porque o melhor, enfim,
É não ouvir nem ver...
Passarem sobre mim
E nada me doer!
- Sorrindo interiormente,
Co'as pálpebras cerradas,
Às águas da torrente
Já tão longe passadas. -
Rixas, tumultos, lutas,
Não me fazerem dano...
(...)
(PESSANHA, 2009, p. 100)

Nesse poema, o eu lírico aspira à comunhão com a terra, como abrigo às dores do mundo, materializadas como conflitos intermináveis, movidos pela vontade. Em um mesmo quadro, o poema apresenta a superfície turbilhonada e, em contraste, o subterrâneo abrigo do eu lírico diluído no húmus, encontrando nele uma plácida alegria, oriunda da ausência das dores.

Já em Pedro Kilkerry a ironia encontra vasto campo de atuação, operando contrastes e configurando estranhas analogias. Além disso, a ironia abre espaço na lírica de Pedro Kilkerry para reflexões sobre as imposições do nada e do silêncio ao verbo poético. O exemplo mais explícito desse procedimento em Kilkerry é o poema "É o silêncio...":

É o silêncio, é o cigarro e a vela acesa. Olha-me a estante em cada livro que olha. E a luz nalgum volume sobre a mesa... Não sei se é mesmo a minha mão que molha A pena, ou mesmo o instinto que a tem presa. Penso um presente, num passado. E enfolha A natureza tua natureza.

Mas é um bulir das cousas... Comovido
Pego da pena, iludo-me que traço

A ilusão de um sentido e outro sentido.

Tão longe vai!

Tão longe se aveluda esse teu passo,

Asa que o ouvido anima...

E a câmara muda. E a sala muda, muda...

Afonamente rufa. A asa da rima

Paira-me no ar. Quedo-me como um Buda

Novo, um fantasma ao som que se aproxima

Cresce-me a estante como quem sacuda

Um pesadelo de papéis acima...

E abro a Janela. Ainda a lua esfia.

Últimas notas trêmulas... O dia

Tarde florescerá pela montanha.

E oh, minha amada, o sentimento é cego...

Vês? Colaboram na saudade a aranha,

Patas de um gato e as asas de um morcego.

(KILKERRY, 1985, p. 117-118)

Aqui a perspectiva autorreferente compõe, por meio de reflexões sobre as dificuldades expressionais, um poema reativo ao silêncio. Em Kilkerry o motivo do silêncio, como manifestação expressiva do nada, sugere a exploração de recursos, hoje considerados metalinguísticos, que nascem sob a égide da ironia, entendida, nesse contexto, como a manifestação da autoconsciência e ruptura dos limites entre a matéria interna do poema e o processo criativo. Processo criativo esse, que no referido poema, surge como tarefa vã de registro do indefinido (a "asa da rima" que paira) e do fugidio (o "sentido" apreensível apenas como ilusão), que encontram correspondência na saudade que preenche a câmara vazia com a "presentificação" do passado - expressão máxima da atmosfera fantasmagórica do poema. $\mathrm{O}$ ato de escrever converge, pois, na obsessiva figuração de fantasmas que se vale, inclusive, dos contornos sugestivos do imaginário popular sobre a magia negra - os "ingredientes" desse poema de saudade, realizável apenas no testemunho de seu processo de composição frustrado são a "(...) aranha, patas de um gato/ e as asas de um morcego". Imagens herméticas, dotadas de uma surpreendente ironia que quebra a dicção regular do poema, ligando-se a sua atmosfera pelos nexos da desolação e do silêncio materializados, metonimicamente, na evocação do ofício silencioso de tecitura da teia de aranha, bem como dos igualmente silenciosos passos do gato e voo do morcego - eis os componentes fantasmagóricos, materializações concretas das ausências que paradoxalmente nutrindo-se da matéria prima das ausências, geram um poema resistente ao nada.

Em comum entre os recursos irônicos articulados por Camilo Pessanha e Kilkerry está a evocação das impressões cotidianas, ora ordinárias, ora grotescas, utilizadas como caminhos para a eclosão do sublime. Embora seus poemas também trabalhem com imagens convencionalmente relacionadas à imagética do sublime 
(como o mar, os céus noturnos, o movimento das estações, a morte, etc.), não se limitam à descrição da grandiosidade a eles inerente, mas optam por plasmar seus vestígios fragmentários; Camilo Pessanha e Pedro Kilkerry contemplam os objetos sublimes de um mirante parcial e pouco privilegiado, deixando uma vasta lacuna para o entendimento. Desse modo, o mistério se instaura e a beleza se encaminha para além da compreensão, transcendendo os limites da expressão e sugerindo seus contornos ideais.

Ora, a experiência romântica ensinou aos poetas que seguiram suas trilhas que a distância entre as "ideais puras" e a possibilidade de concretizá-las é deveras acentuada. Como tal, tematizar o nada seria uma forma de confrontá-lo e salvar a expressão do vazio; por conta disso, poetas conscientes dos meandros complexos do idealismo optaram pela sugestão e pela abordagem indireta do ideal; pautando-se nas impressões, concederam voz ao fenômeno contemplado em sua parcialidade (STEINER, 1988, p. 66). Camilo Pessanha e Pedro Kilkerry estão entre os primeiros poetas em língua portuguesa que demonstraram tal consciência, o que lhes garantiu espaço singular no plano de suas literaturas nacionais, podendo ser considerados como duas das vozes mais originais do simbolismo em língua portuguesa.

\section{Referências}

BAUDELAIRE, Charles. Les Fleurs du Mal. Rio de Janeiro: Libraire Victor, 1942.

BENJAMIN, Walter. Magia e Técnica, Arte e Política. Ensaios Sobre Literatura e História da Cultura. Obras Escolhidas. São Paulo: Brasiliense, 1994.

BURKE, Edmund. Uma investigação filosófica sobre a origem de nossas idéias do sublime e do belo. Tradução de Enid Abreu Dobianszky. São Paulo: UNICAMP, Papiros, 1993.

CALINESCU, Mattei. Cinco caras de la modernidad. Madrid: Editorial Tecnos, 1991.

CAMPOS, Augusto de. ReVisão de Kilkerry. São Paulo: Brasiliense, 1985.

COMPAGNON, Antoine. Os cinco paradoxos da Modernidade. Tradução de Cleonice P. B. Mourão, Consuelo F. Santiago e Eunice D. Galéry. Belo Horizonte: Ed. UFMG, 1996.

FRANCHETTI, Paulo. Apresentação e notas. In: PESSANHA, C. Clepsidra. São Paulo: Ateliê Editora, 2009.
FRIEDRICH, Hugo. Estrutura da lírica moderna: metade do século XIX a meados do século XX. Tradução de Marisa M. Curioni (texto) e Dora F. da Silva (poesias). São Paulo: Duas Cidades, 1978.

GUIMARÃES, Fernando. Simbolismo, Modernismo e vanguarda. Porto: Lello \& Irmão - Editores, 1992.

KANT, Immanuel. Crítica del judicio. Tradúcion de José Rovira Armengoi. Buenos Aires: Losada, 1961.

KILKERRY, Pedro. ReVisão de Kilkerry. Apresentação, estudos críticos e notas de Augusto de Campos. São Paulo: Brasiliense, 1985.

LONGINO. Do sublime. Tradução de Filomena Hirata. São Paulo: Cultrix/Edusp, 1996.

MUECKE, Douglas Colin. Ironia e o irônico. Tradução de Geraldo de Souza. São Paulo: Perspectiva, 1995. (Debates, 250).

MURICY, José Cândido de Andrade. Panorama do movimento simbolista brasileiro. Rio de Janeiro: Departamento de Imprensa Nacional, 1987.

PAZ, Octavio. Os filhos do barro: do romantismo à vanguarda. Tradução de Olga Savary. Rio de Janeiro: Nova Fronteira, 1994.

PESSANHA, Camilo. Clepsidra. Organização, apresentação e notas de Paulo Franchetti. São Paulo: Ateliê Editora, 2009.

RUBIM, Gustavo. Experiência da alucinação: Camilo Pessanha e a questão da poesia. Lisboa: Editorial Caminho, 1993.

SCHLEGEL, Friedrich. Conversa sobre a poesia e outros fragmentos. Tradução, prefácio e notas de Victor-Pierre Stirnimann. São Paulo: Iluminuras, 1994 (Biblioteca Pólen).

SCHOPENHAUER, Arthur. Metafísica do belo. Tradução, apresentação e notas de Jair Barbosa. São Paulo: Editora UNESP, 2003.

STEINER, Georges. Linguagem e silêncio: ensaios sobre a crise da palavra. Tradução de Gilda Stuart e Felipe Rajabally. São Paulo: Companhia das Letras, 1998.

VATTIMO, Gianni. O fim da Modernidade: Niilismo e Hermenêutica na pós-modernidade. Tradução de Maria de Fátima Boavida. Revisão científica de Luíza Costa Gomes, B. J. de Almeida Faria, Mário Jorge de Carvalho e Pedro Paixão. Lisboa: Presença, 1987.

WEISKEL, Thomas. O sublime romântico: estrutura e psicologia da transcendência. Tradução de Patrícia Flores da Cunha. Rio de Janeiro: Imago, 1994.

Recebido: 15 de agosto 2014 Aprovado: 05 de novembro 2014 Contato: fabianorssantos@yahoo.com.br 